LA-7620-MS

Informal Report

UC-34c

Issued: January 1979

Fission Product Gamma Spectra

\author{
E. T. Jurney \\ P. J. Bendt \\ T. R. England
}

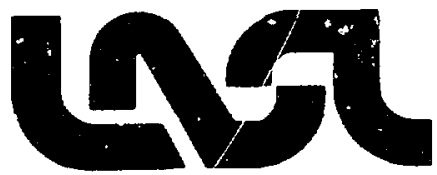

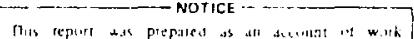

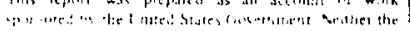

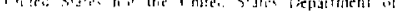

,... Jin

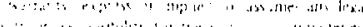

and 


\section{FISSION PRODUCT GAMMA SPECTRA}

by

E. T. Jurney, P. J. Bendt, and T. R. England

\section{ABSTRACT}

The fission product gamma spectra of ${ }^{23}{ }^{3} \mathrm{U}$, $2{ }^{3} \mathrm{U}$, and $2{ }^{99} \mathrm{Pu}$ have been measured at 12 cooling times following $20000-s$ irradiations in the tr.ermal column of the Omega West Reactor. The mean cooling times ranged from $29 \mathrm{~s}$ to $146500 \mathrm{~s}$. The total gamma energies were obtained by integrating over the energy spectra, and both the spectra and the total energies are compared with calculations using the CINDER-10 code and ENDF/B-IV data base.

The measured and calculated gamma spectra are compared in a series of figures. The measured total gamma energies are $\sim 14 \%$ larger than the calculated energies during the earliest counting period ( $4 \mathrm{~s}$ to $54 \mathrm{~s}$ cooling time). For ${ }^{235} \mathrm{U}$, the measured and calculated total gamma energies are nearly the same after $1200 \mathrm{~s}$ cooling time, and the measurements are $2 \%$ to $6 \%$ lower at longer cooling times. For ${ }^{239} \mathrm{Pu}$, the measured and calculated total gamma energies are nearly the same at cooling times longer than $4000 \mathrm{~s}$, and for ${ }^{23} \mathrm{U}$ this condition prevails at cooling times longer than $10000 \mathrm{~s}$.

\section{INTRODUCTION}

The fission product gamma spectra of ${ }^{233} \mathrm{UJ},{ }^{235} \mathrm{U}$, and ${ }^{239} \mathrm{Pu}$ have becn measured at 12 cooling times following 20 000-s irradiations in the thermal column of the Omega Hest Reactor. The radiation period was long enough to build up a near-equilibrium concentration of the shorter half-life fission products. The constant neutron flux was abruptly cut off at the end of each irradiation. 

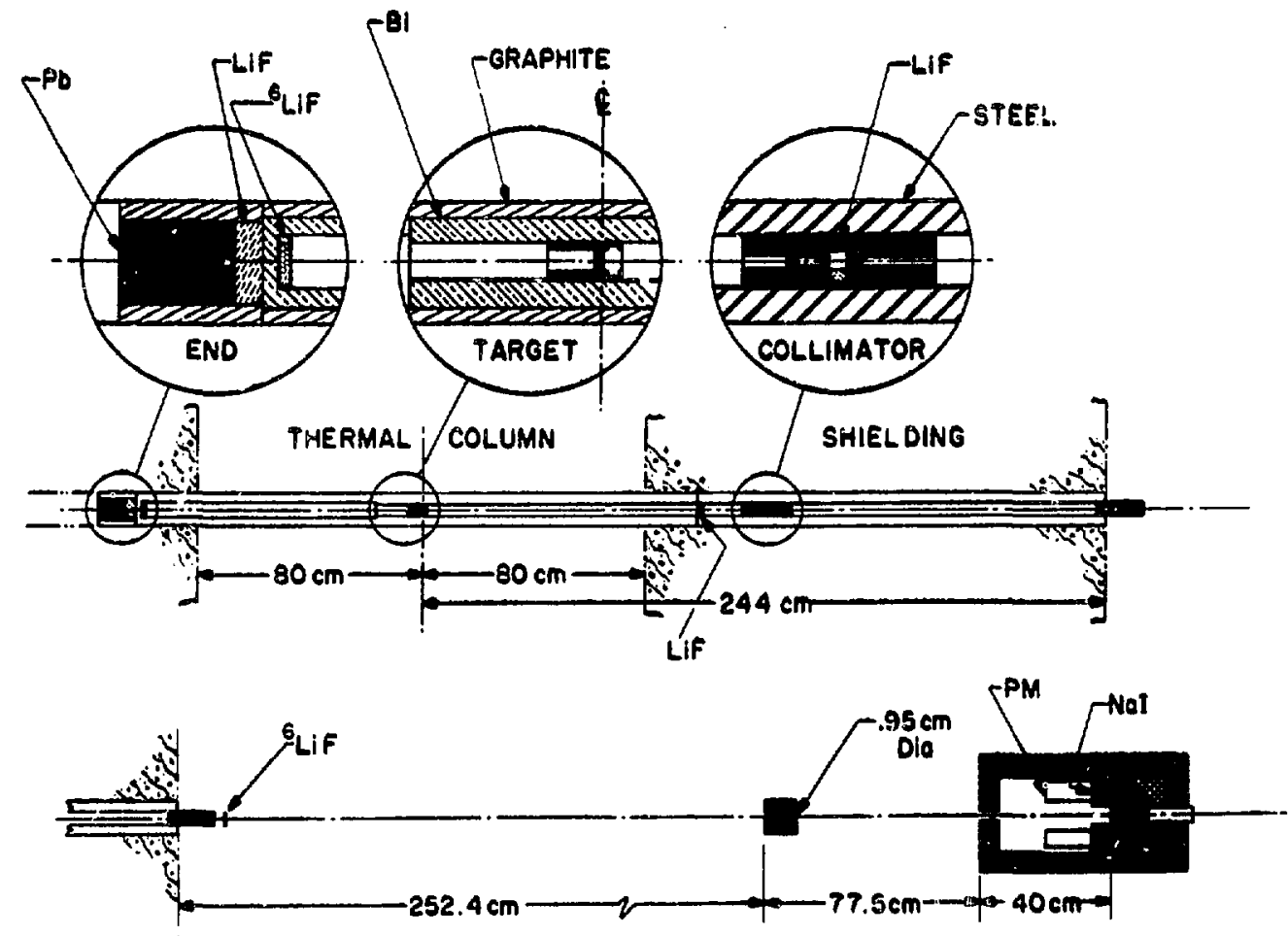

Fig. 1. Plan view of the gamma spectrometer. The continuation of the beam path outside the reactor shielding is shown below. The graphite holder is shown in the middle circle.

The mean cooling times ranged from $29 \mathrm{~s}$ to $146500 \mathrm{~s}$. The total gamma energies were obtained by integrating over the energy spectra, and both the spectra and the total energies are compared with caloulations using the CINDER-10 code and ENDF/B-IV data base.

The present work was initiated in connection with cryogenic calorimetric measurements of the fission product decay heat. ${ }^{1,2}$ The gamma and beta spectra from ${ }^{235} \mathrm{U}$ and ${ }^{239} \mathrm{Pu}$ fission products following 1- to 100-s irradiations have been measured by Dickens et al ${ }^{3,4}$ at cooling times between 2 and $14000 \mathrm{~s}$.

\section{THE REACTOR AND SPECTROMETER}

The Omega West Reactor is a light-kater, thermal-neutron reastor using a central core of Materials. Testing Reactor type fuel elements containing 
enriched uranium. A 76-mm-thick lead shield adjacent to the core and a 127mm-thick bismuth shield inside the thermal column prevent photons originating in the core from reaching the sample in the thermal column.

A bismuth-walled evacuated channel, in which the sample is placed, extends through the thermal column, as shown in Fig. 1. The bismuth attenuates the equilibrium thermal-column gamma flux at the sample position, and collimation prevents gammas originating in the channel. walls from reaching the detector. The sample is located $6.14 \mathrm{~m}$ from the detector, and the photon beam is collimated to approximately $1-\mathrm{cm}$ diameter at the detector. The detector was a $6.35-\mathrm{cm}-\mathrm{diam}$ by $15-\mathrm{cm}-1$ long $\mathrm{NaI}(\mathrm{Tl})$ crystal located inside a 25-cm-diam by 30-cm-long NaI(TI) annulus, used in anticoincidence (total energy mode). The entire detector was enclosed in a $7.6-\mathrm{cm}-$ thick lead and iron shield, as shown in Fig. 1.

During sample irradiations, the reactor power was held constant at $B \mathrm{MW}$, corresponding to a thermal neutron flux of $6 \times 10^{11} \mathrm{n} / \mathrm{cm}^{2} \mathrm{~s}$ at the sample. The thermal flux approximates a Maxwellian distribution corresponding to a temperature of $350 \mathrm{~K}$, for which the most probable neutron velocity is $2400 \mathrm{~m} / \mathrm{s}$.

\section{II1. THE SAMPLES}

The weight and isotopic composition of the fissionable samples is given in Table I. The ${ }^{233} \mathrm{U}$ and ${ }^{235} \mathrm{U}$ samples were 6.35 -mm-diam disks, and the ${ }^{239} \mathrm{Pu}$

TABLE I

WEIGHT AND COMPOSITION (IN WEIGHT PER CENT) OF THE SAMPLES

\begin{tabular}{|c|c|c|c|c|}
\hline Sample & $\begin{array}{c}\text { Weight } \\
\mathrm{ngg}\end{array}$ & $\begin{array}{l}\text { Chemical } \\
\text { Composition }\end{array}$ & Isotope & $\begin{array}{l}\text { Isotopic } \\
\text { Composition }\end{array}$ \\
\hline${ }^{233} \mathrm{U}$ & 1.73 & $U=100 \%$ & $\begin{array}{l}U-233 \\
U-234 \\
U-235 \\
U-236 \\
U-238\end{array}$ & $\begin{array}{l}97.46 \mathrm{w} / \mathrm{o} \\
1.15 \\
0.29 \\
0.04 \\
1.06\end{array}$ \\
\hline $235_{U}$ & 2.14 & $U=100 \%$ & $\begin{array}{l}U-234 \\
U-235 \\
U-236 \\
U-238\end{array}$ & $\begin{array}{l}0.87 \mathrm{w} / \mathrm{o} \\
93.19 \\
0.48 \\
5.46\end{array}$ \\
\hline${ }^{239} \mathrm{Pu}$ & ther & $\begin{array}{l}P u=99.37 \mathrm{w} / 0 \\
\mathrm{tes}=0.63\end{array}$ & $\begin{array}{l}P u-238 \\
P u-239 \\
P u-240 \\
P u-241 \\
P u-242\end{array}$ & $\begin{array}{c}0.04 \mathrm{w} / 0 \\
93.59 \\
6.02 \\
0.32 \\
0.03\end{array}$ \\
\hline
\end{tabular}


sample was a 4.76-mm-diam disk, all three cut from 0.025-mm-thick foils. They were sealed between $0.125-\mathrm{mm}$-thick aluminum disks cf larger diameter. The aluminum disks holding the uranium foils were electron-beam welded around the perimeter, while the plutonium disk was sealed between aluminum disks with

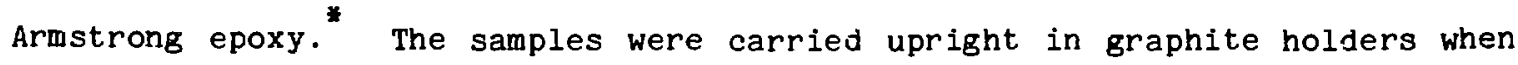
inserted into the thermal column. No leakage of gaseous fission products was detected by radiation monitors adjacent to the exhaust line from the pump that evacuated the thermal column channel.

Dummy samples consisting of aluminum disks and epoxy where appropriate were also irradiated and counted. The dummy sample spectra were later subtracted from the fissionable isotope spectra.

\section{STRIPPING THE GAMMA SPECTRA}

The pulse-height distribution from the detector during a counting period was accumulated in a pulse-height analyzer and read onto magnetic tape for processing by computer. The computer stripping code takes account of the following unwanted features in the response of the NaI(T1) crystal to a gamma line: (1) bremsstrahlung escape pulses on the low-energy side of the fullenergy peak; (2) the Compton edge, a small peak below the full-energy peak; (3) the flat distribution of Compton-scattered photons below the Compton edge; (4) the first and second annihilation radiation escape peaks; and (5) a backscattering peak, at $\checkmark 200 \mathrm{keV}$. The stripping starts at the high-energy end of pulse-height distribution, treating the top bin as a portion of a full-energy peak, and reduces the counts in the lower energy bins by an amount determined by the response function. The process is repeated successively for the lower energy bins.

\section{v. CALCULATING GAMMA POWER FROM THE MEASUREMENTS}

Befcre: irradiating dch fissionable target, a 44.2-mg sample of polyethylene $\left(\mathrm{CH}_{2}\right)_{n}$ was irradiatct, and the hydrogen capture gamma ray at $2.223 \mathrm{MeJ}$ $\left(=E_{H}\right)$ was counted by the spectrometer for a convenient period. The fissionable target was then irradiated in the same neutron flux for $20000 \mathrm{~s}$, after

\footnotetext{
* Armstrong Products Co., Argonne Road, Warsaw, IN. Type 1-A resin with activator $A$ was used.
} 
which the reactor was abruptiy shut down. This procedure enabled us to calibrate the spectrometer in terms of unit reaction cross section for a constant neutron flux, since the $(n, \gamma)$ cross section for ${ }^{1} \mathrm{H}$ is accurately knowm. The gamma power at cooling time $t, I(E, t)$ per unit fission rate per unit energy interval about $E$, is given by

$$
I(E, t)=\frac{G(E, t) E E\left(E_{H}\right) N_{H} o_{H}(n, \gamma)}{G\left(E_{H}\right) E(E) N_{U} \sigma_{U}(f i s s)}
$$

where $G\left(E_{H}\right)$ is the gamma counting rate recorded by the spectrometer for the hydrogen capture line, and $G(E, t)$ is the gamma counting rate recorded in the 50-keV energy interval about $E$. The function $E(E)$ is the relative efficiency of the spectrometer at energy $\mathrm{E} . \quad \mathrm{N}_{\mathrm{H}}$ and $\mathrm{N}_{\mathrm{U}}$ are the number of hydrogen and uranium (or plutonium) atoms.

Except for ${ }^{23 \dot{3}} \mathrm{U}$, the a(fiss) used in Eq. 1 are not $1 / \mathrm{v}$ cross sections. We have therefore integrated the $\sigma(f i s s)$ and the neutron absorption cross sections a(abs) over a Maxwellian thermal neutron distribution having a most probable velocity of $2400 \mathrm{~m} / \mathrm{s}$. The $\sigma(a b s)$ were used to calculate a correction for self-absorption and for neutron-flux depression at the location of the samples. For those cross sections which are $1 / v$, the meen velocity of the Maxwellian distribution is $2 / \sqrt{\pi}$ times 2400 , which equals $2708 \mathrm{~m} / \mathrm{s}$. The cross sections used are given in Table Il, and are based on curves given in ENL-325. 5

TABLE II

NEUTROA ABSORPTION CROSS SECTIONS ANO QUANTITIES OBTALNEO BY SUMMING OVER THE SPECTRA FROM $50 \mathrm{keV}$ to $7 \mathrm{MeV}$

\begin{tabular}{|c|c|c|c|c|c|}
\hline Isotope & $\begin{array}{c}\sigma_{\text {abs }} \\
\text { barns }\end{array}$ & $\begin{array}{l}\text { Multiplicity } \\
x^{\prime} \text { s/neutron }\end{array}$ & $\begin{array}{l}\text { Spectral Surn } \\
\text { barns } \times \text { MeV }\end{array}$ & $\begin{array}{l}\text { Energy Released } \\
\text { MeV/neutron }\end{array}$ & $\begin{array}{c}\text { Average Photon Energy } \\
\text { MeV/photon }\end{array}$ \\
\hline $233_{U}$ & 470 & $14.6 \pm 0.3$ & $6920 \pm 248$ & $14.7 \pm 0.5$ & $1.01 \pm 0.06$ \\
\hline $235 u$ & 533 & $13.6 \pm 0.3$ & $6918 \pm 238$ & $13.0 \pm 0.4$ & $0.95 \pm 0.05$ \\
\hline${ }^{239} \mathrm{Pu}$ & 887 & $11.2 \pm 0.3$ & $9200 \pm 243$ & $10.4 \pm 0.3$ & $0.92 \pm 0.05$ \\
\hline$I_{H}$ & $0.270^{a}$ & 1.0 & & & 2.22 \\
\hline
\end{tabular}

The BNL-325 value for $22.00 \mathrm{~m} / \mathrm{s}$ neutron velocity is 0.332 barns. 
The results are given as tables of gamma power in $\mathrm{MeV}$ per second, per energy interval, at cooling time $t$, divided by the number of fissions per second during the irradiation. The units $\mathrm{MeV}$ per second divided by fissions per second are conventionally called MeV/fission, even though the denominator refers to the rission rate during neutron irradiation and the numerator refers to a rate after the reactor was shut down. Each value is given with an unsertainty, which includes a $1^{\sigma}$ statistical uncertainty in quadrature with a $\pm 10 \%$ uncertainty assigned to the response function used in stripping the spectra. The spectra have also been summed over the 50-keV energy bins from zero to 6 MeV to ootain the total gamma power at cooling time $t$.

\section{GAMMA SPECTRA CALCULATED FROM FISSION PRODUCT NUCLIDES}

In the next section we inciude comparisons of the measurements with calculated spectra and with total gamma energy release rates. Calculated spectra are obtained using the CINDER-10 code to generate activities and total gamma decay energies. The activities are folded into multigroup energy spectra using an auxiliary routine which is a modification of FPSPEC. 6 CINDER-10 is not documented but is an extensive modification of CINDER-7. 7 The spectra, . ission yields and all decay parameters used in CINDER-10 are processed from Version IV of the fission-product Evaluated Nuclear Data Files (ENDF/B-IV), 8 except for data corrections noted in Ref. (9). There are 824 nuclides in the ENDF/B-IV fission product file, 711 being unstable. Gamma energies and intensities are included for 180 of the unstable nuclides; as will be shown in the next section, this subset contributes most of the total calculated gamma energy for the cooling tines covered by the measurements. All unstable nuclides contain a total gamma energy; these and all other ENDF/B-IV fission product parameters (branching fractions, decay constants, fission yields, cross sections, etc.), are incorporated into the CINDER-10 Iibrary. The calculations are then made for the specific irradiation history of the fission samples and the spectra subsequent to irradiation are calculated at the mid-point of each counting period. The calculations do not have any significant approximation but are dependent on the completeness and quality of the nuclide data. The comparisons in the next section indicate the quality and completeness of the calculated spectra; this section itemizes the more significant aspects considered in the calculations. 
For each of the 180 nuclides havirg spectra data, the gamma energies are first broadened to match the resolution and energy dependerse of the speotrometer using a Gaussian distribution about each gamma energy, $E_{0}$, and having an area equal to the irtensity per decay, I:

$$
G=\frac{I}{\sigma / 2 \pi} \exp -\left[\frac{\left(E-E_{0}\right)^{2}}{2 \sigma^{2}}\right] \text {. }
$$

(In this experiment, $\sigma=-2+0.47 \mathrm{~V}$, where $E$ is in keV.) The subsequent distributions are then grouped into 150 energy bins on a uniform $50 \mathrm{keV}$ grid between 0 and $7.5 \mathrm{MeV}$. In this report we have grouped the energies, not the pioton multiplicities, per bin. Plots of the resulting spectra then visually display the energy release over the energy axis.

We have assumed that the spectral shape is determined by the 180 nuclides having spectral data in ENDF/B-IV and have normalized the aggregate gamma spectra to provide the total value calculated by CINDER-10.

Measured spectra are based on a finite counting time but calculations apply to specific decay times. For energy-integrated comparisons, we rave examined the difference between using a time average of the calculated values over the counting period and the energy release rate at the midpoint of the period. The mid-point value is $s 1 \%$ smaller than the time-averaged value. This evaluation was made before the final measurements and did not include the subsequent 4-54 s counting interval. For this period we have calculated the mid-point release rate to be nearly 5\% smaller than the time-averaged value. These differences are not removed in the tabular comparisons of the integrated spectra.

\section{RESULTS}

The schedule of counting periods following reactor shutdown is given in Table III. The successive counting pericds are identified on the figures and in the tables of results by the midpoint values of the periods.

The total gamma energies at the various cooling times are given in Table IV. The last column under each isotope in Table IV gives the per cent of the total calculated energy which is contributed by the 180 nuclides. The results in Table IV apply only to a 20 000-s irradiation at constant power. 
TABLE III

SCHEDULE OF COUNTING PERIODS AFTER REACTOR SHUTDOWN

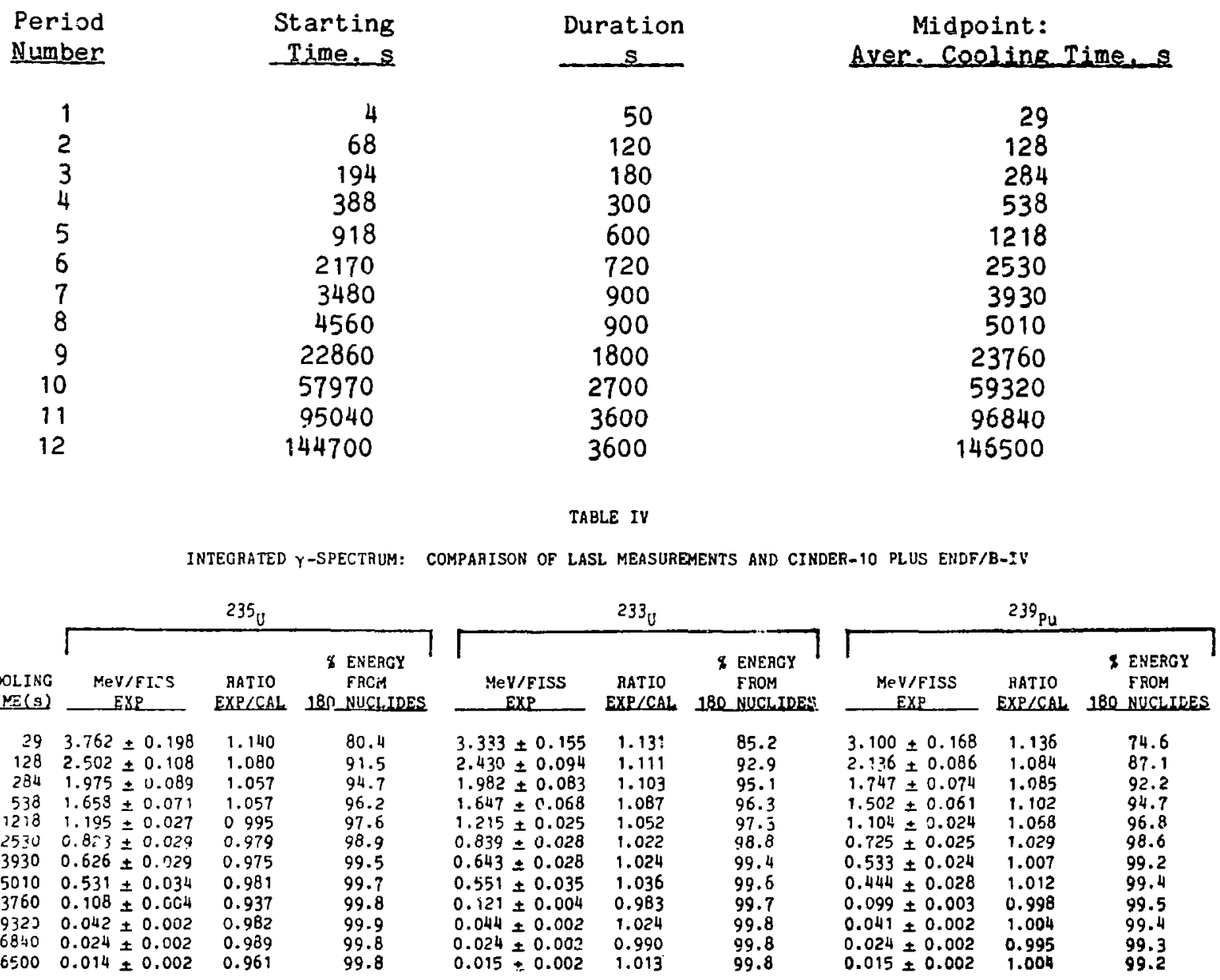

ENDF, B-IV files contain internal electron conversion coefficients for 38 important nuclides. The spectral comparisons do not include these conversion energies and the tabular comparisons of the energy-integrated spectra are given without the internal conversion energies. However, only the conversion energies of the 38 nuclides having internal conversion coefficients in ENDF/B-IV were excluded.

Bendt and Jurney ${ }^{10}$ have al so made gamma-power Eeasurements (after 20000 s) while the irradiation of the fissionable isotopes continued. Peelle and Maienschein" have measured the prompt photon energy in coincidence with fission fragments, for $235 \mathrm{U}$. Combining these measurements results in a gamma power from fission products at zero time equal to $6.9 \pm 0.7 \mathrm{MeV} / \mathrm{fiss}$ on (for 


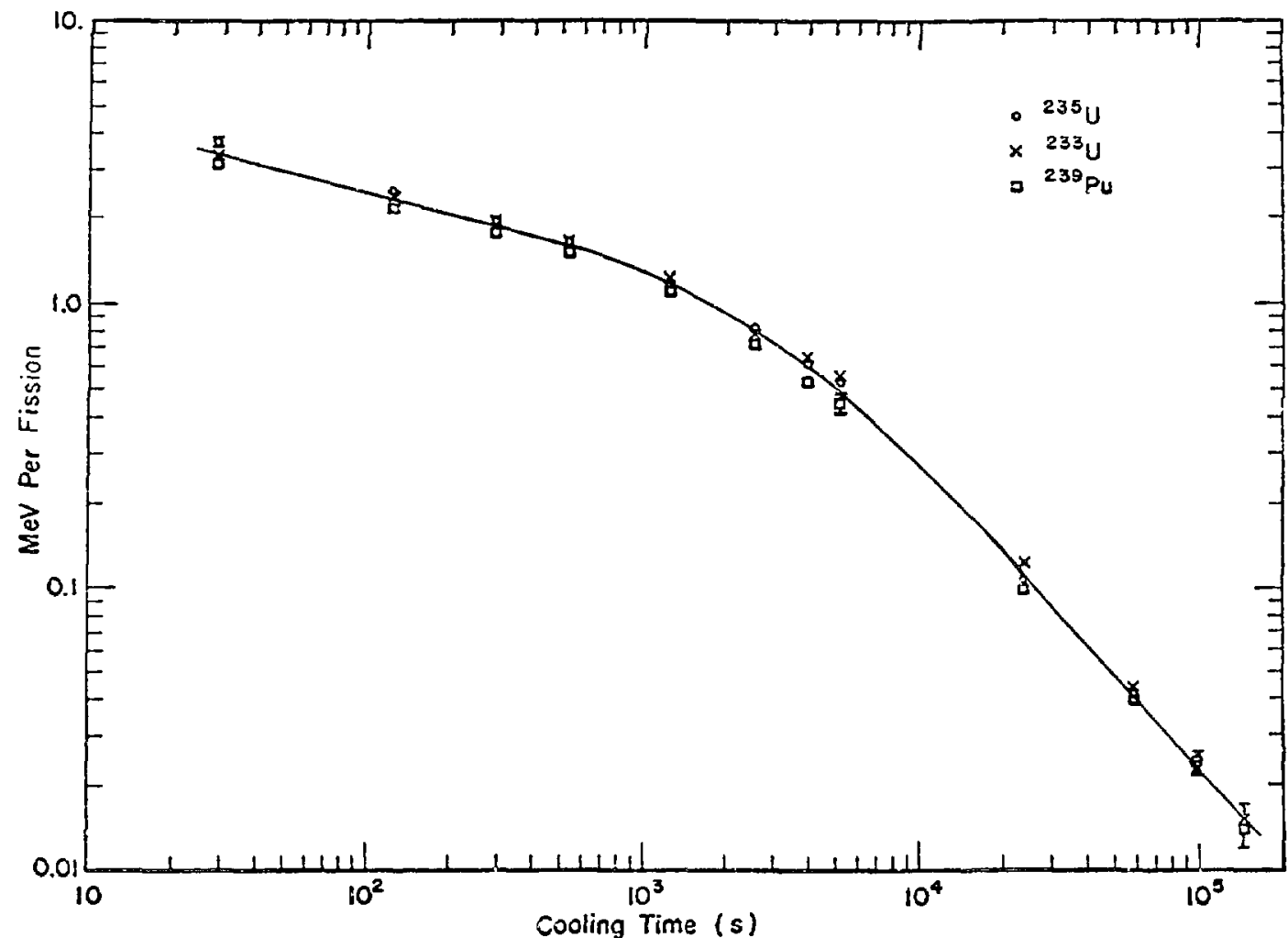

Fig. 2. The experimental gamma power of the fissionable isotopes versus cooling time. Representative error bars are shown nn a fow points.

$235(U)$. This quantity could be obtained for the other isotopes if the prompt photon energy released at the time of fission were measured.

Two figures show the results given in Table IV. Figure 2 shows the experimental total gamna power of the fissionable isotopes plotted versus cooling time. In Fig. 3, the difference between the measurements and calculations, as a percent of the measured values, is plotted against cooling time. The trend shown in Fig. 3, from s $12 \%$ at $29 \mathrm{~s}$, to values around zero percent and lower, at times longer than $1000 \mathrm{~s}$, is not understood.

Figures 4 through 39 (at end of report) show the measured spectrum in $\mathrm{MeV} / \mathrm{fission} / 50 \mathrm{keV}$ bin, and the calculated spectrum as a continuous line, fo. each isotope and cooling time.

\section{ACKNOWLEDGMENTS}

We wish to thank M. G. Stamatelatos and N. L. Whittemore for substantial assistance with the CINDER-10 code calculations and the operating staff of the Omega West Reactor for their help with the special inradiations. 


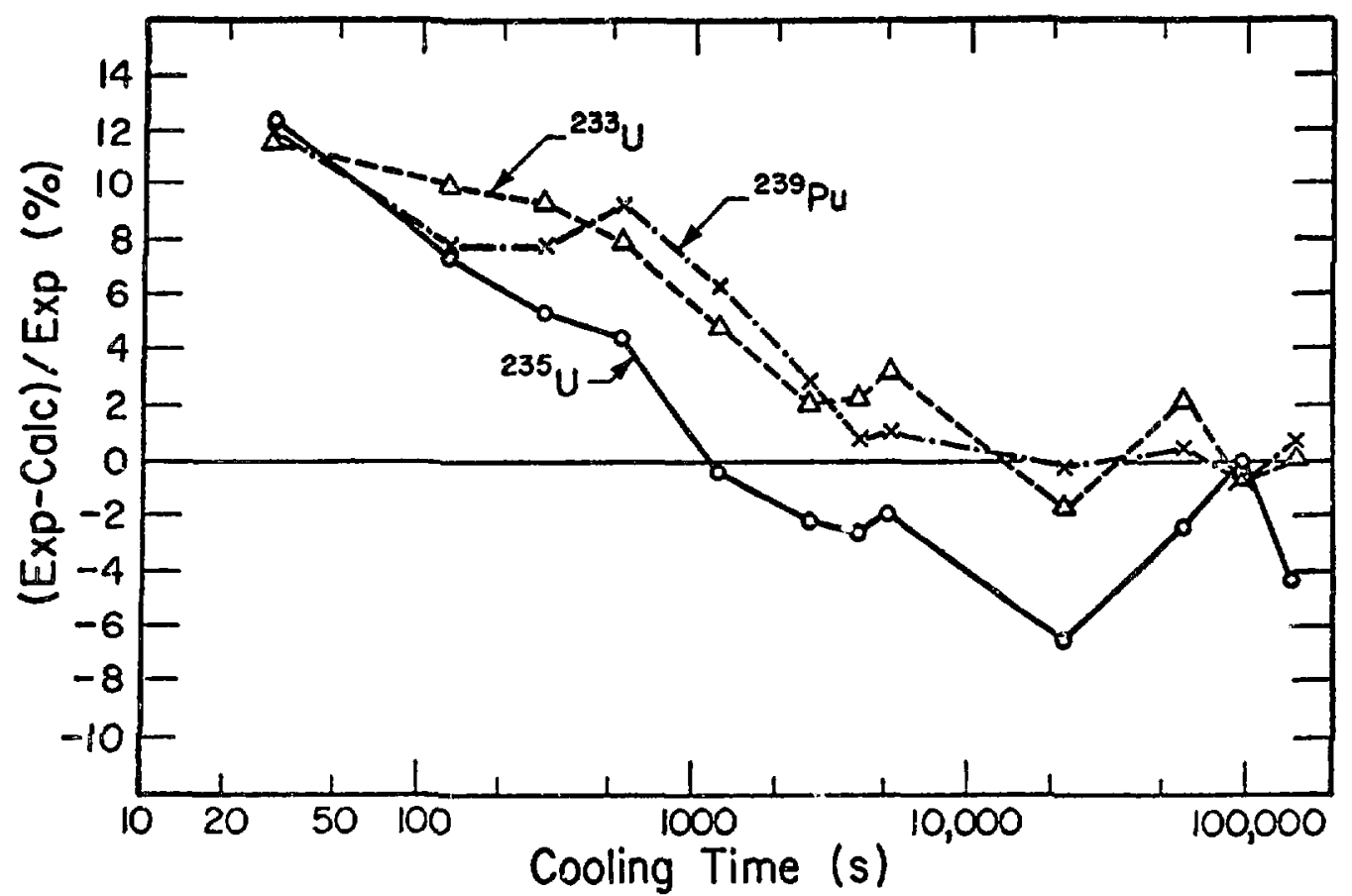

Fig. 3. Difference between the experimental and calculated gamma power, as a percent of the experimental vallies, versus cooling time.

\section{REFERENCES}

1. J. L. Yarnell and P. J. Bendt, "Decay Heat From Products of 235 Thermal Fission by Fast-Response Boil-Off Calorimetry," LA-NUREG-6713 (September $1377)$.

2. J. L. Yarnell and F. J. Bendt, "Calorimetric Fission Product Decay Heat," LA-7452-MS [NUREG/CR-0349] (September 1978).

3. J. K. Dickens, J. F. Emery, T. A. Love, J. W. McConnell, K. J. Northoutt, R. H. Peelle, and H. Weaver, "Fission-Product Energy Release for Times Following Thermal-Neutron Fission of ${ }^{235} \mathrm{U}$ Between 2 and 14000 seconds," ORNL/NUREG-14 (October 1977).

4. J. K. Diskens, J. I. Emery, T. A. Love, J. W. MoConnel1, K. J. Northeutt, R. W. Peelle, and H. Weaver, "Fission-Product Energy Release for Times Following Thermal-Neutron Fission of ${ }^{239} \mathrm{Pu}$ Between 2 and 14000 Seconds," ORNL/NUREG-34 (April 1978). 
5. "Neutron Cross Sections" Brookhaven National Laboratory report BNL 325, third edition, Vol. 2 (January 1976).

6. M. G. Stamatelatos and T. R. Engiand, "FPDCYS and FPSPEC, Computer Programs for Calculating Fission-Product Beta and Gamma Multigroup Spectra from ENDF/B-IV Data," Los Alames Scientific Laboratory report LA-NUREG6818-MS (May 1977).

7. T. R. England, R. Hilczynski, and N. L. Whittemore, "CINDER-7: An Interim Heport for Users," Los Alamos Scientific Laboratory report LA-5885-MS (April 1975).

8. "Fission Product Decay Library of the Evaluated Nuclear Daia File, Version I.V (ENDF/B-IV)." [Available from, and maintained by, the National Nuclear Data Center (NNDC) at the Brookhaven National Laboratory].

9. T. R. England and R. E. Schenter, "ENDF/B-IV Fission-Product Fies: Sumary of Major Nuclide Data," LA-6116-MS [ENDF-223], (October 1975).

10. P. J. Bendt and E. T. Jurney, "Gamma Spectra from ${ }^{233} \mathrm{U},{ }^{235} \mathrm{U}$, and ${ }^{239} \mathrm{Pu}$ During Thermal Neutron Irradiation," Los Alamos Scientific Laboratory report LA-7451-MS (August 1978).

11. R. H. Peelle and F. C. Maienschein, "Spectrum of Photons Enitted in Coincidence with Fission of ${ }^{235}$ U by Thermal Neutrons," Phys. Rev. C3, 373 (1971). 


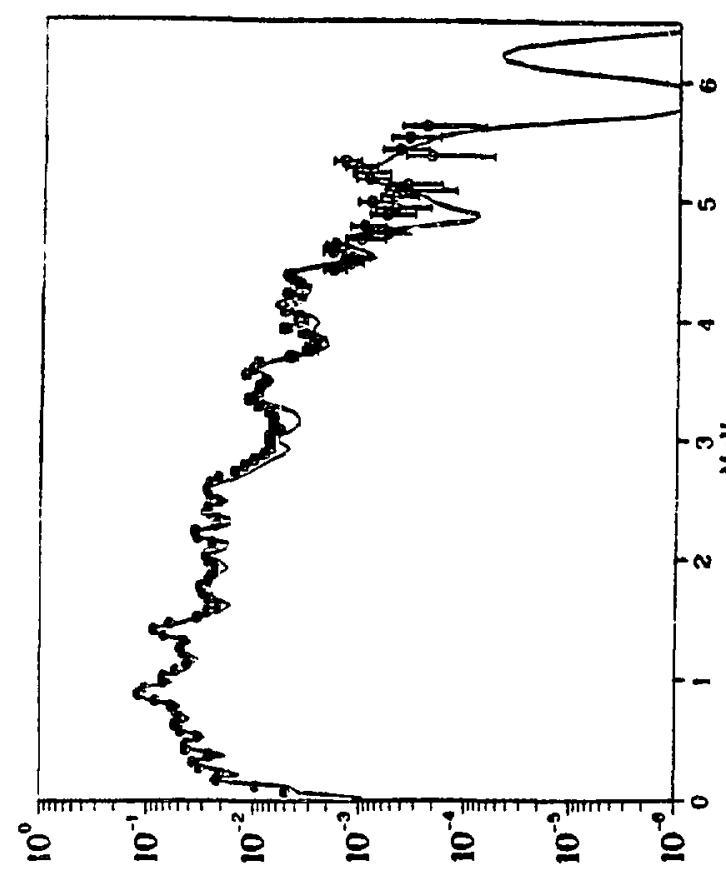

uष̣/uo!ss! //

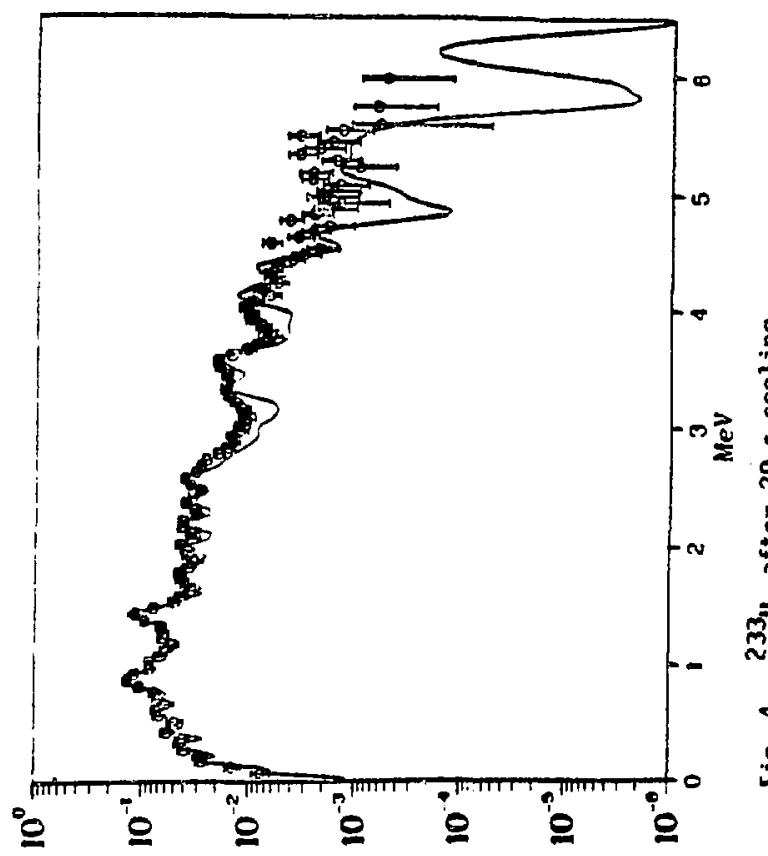

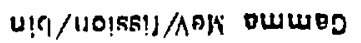

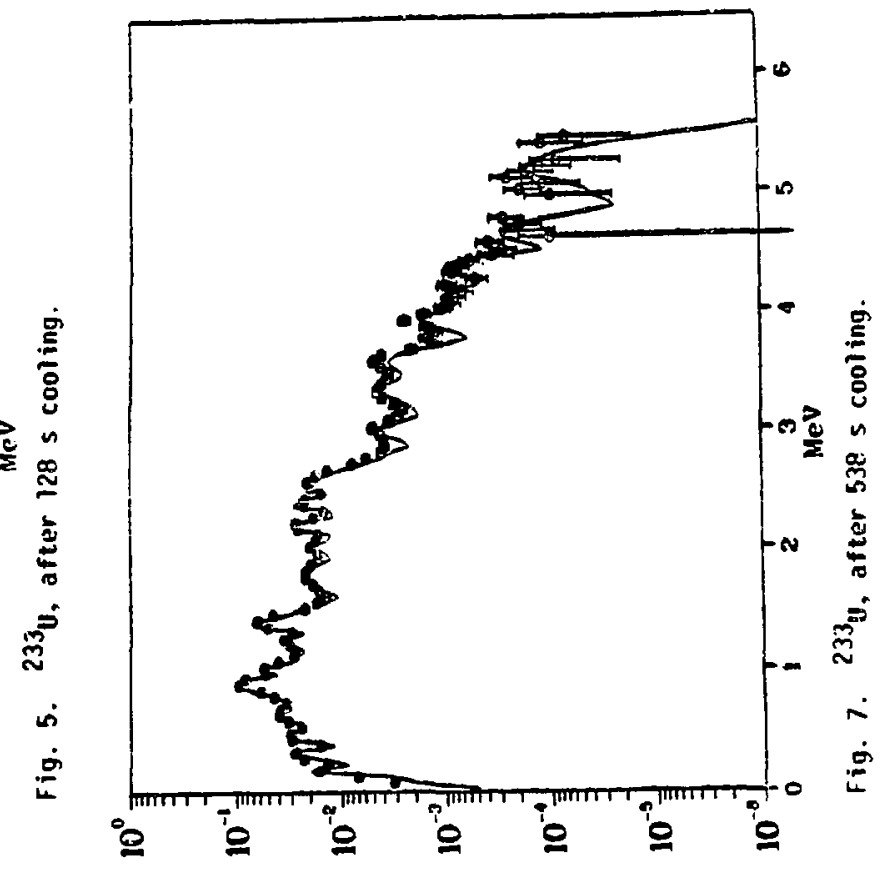

uṭ/uotss!//hoN ewmeD 


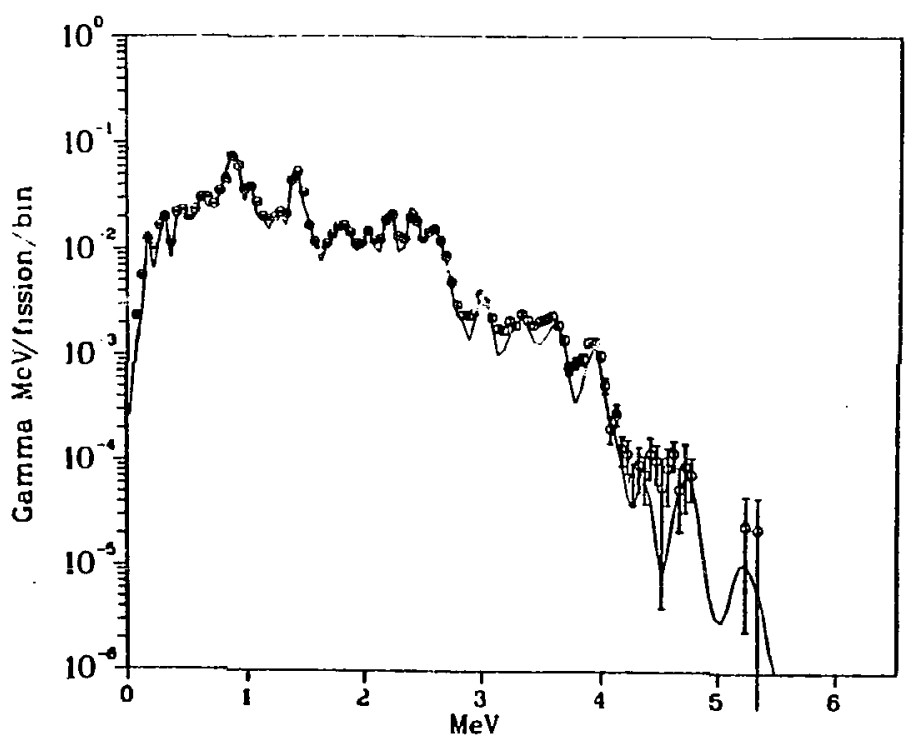

Fig. 8. ${ }^{233} \mathrm{U}$, after $1218 \mathrm{~s}$ cooling.

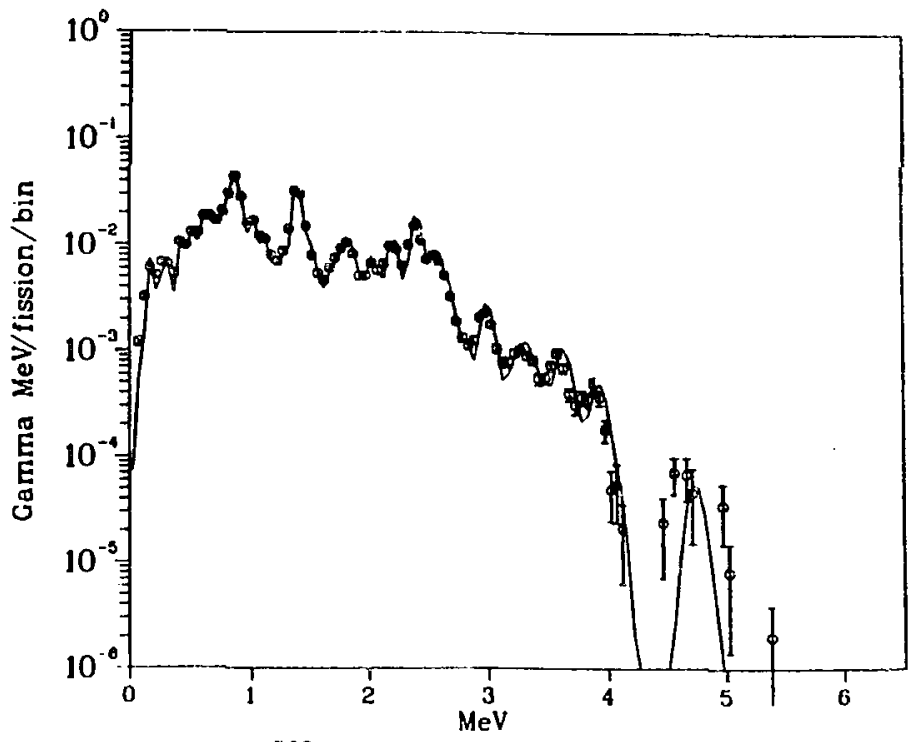

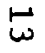

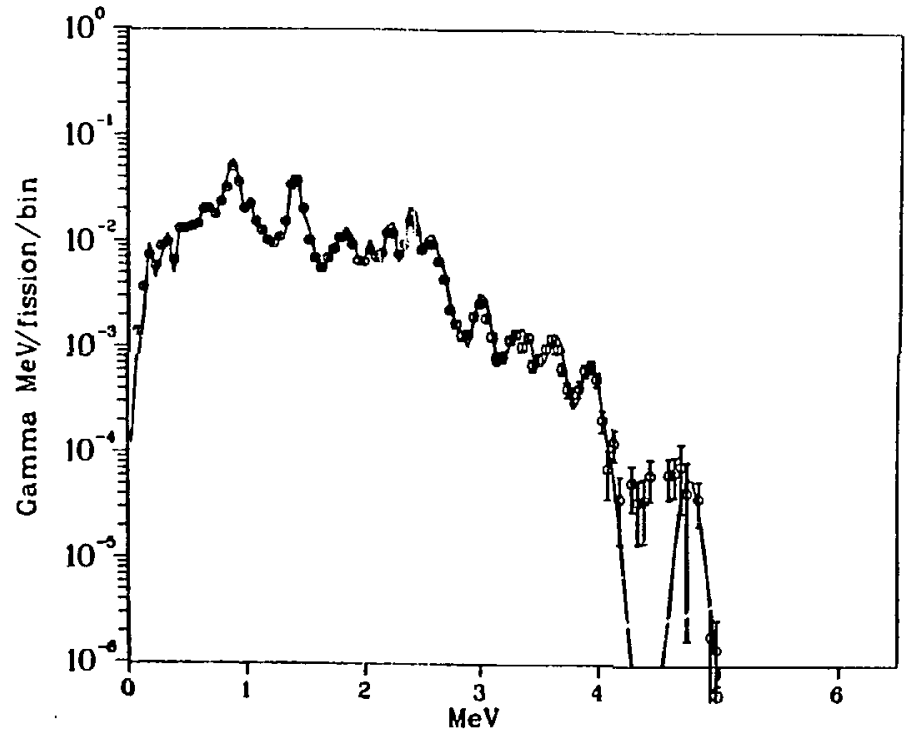

Fig. 9. ${ }^{233} \mathrm{U}$, after $2530 \mathrm{~s}$ cooling.

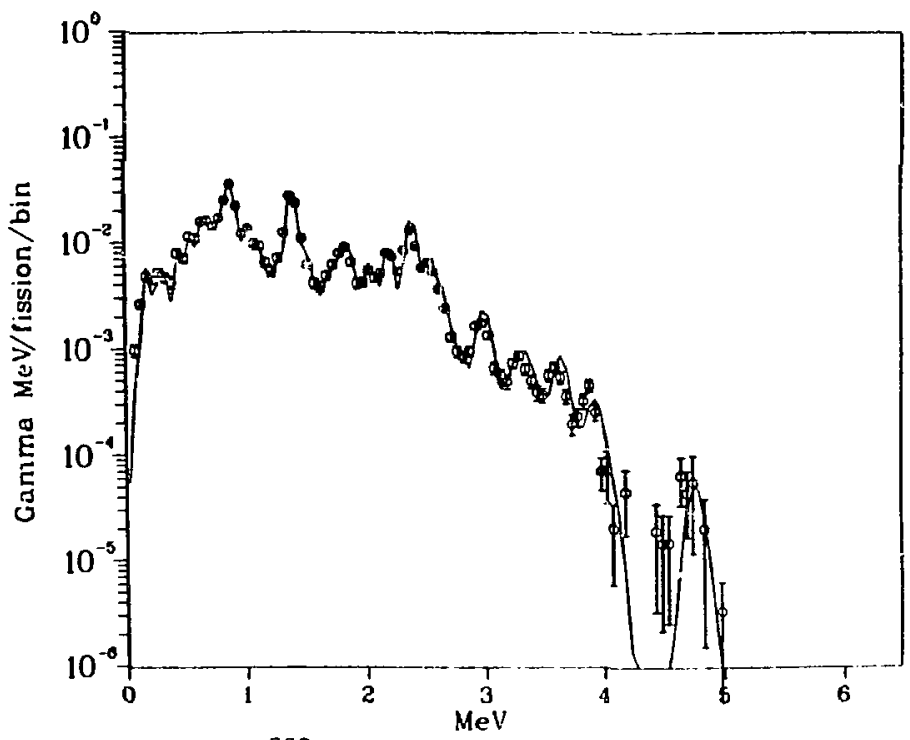

Fig. 11. ${ }^{233} \mathrm{U}$, after $5010 \mathrm{~s}$ cooling. 

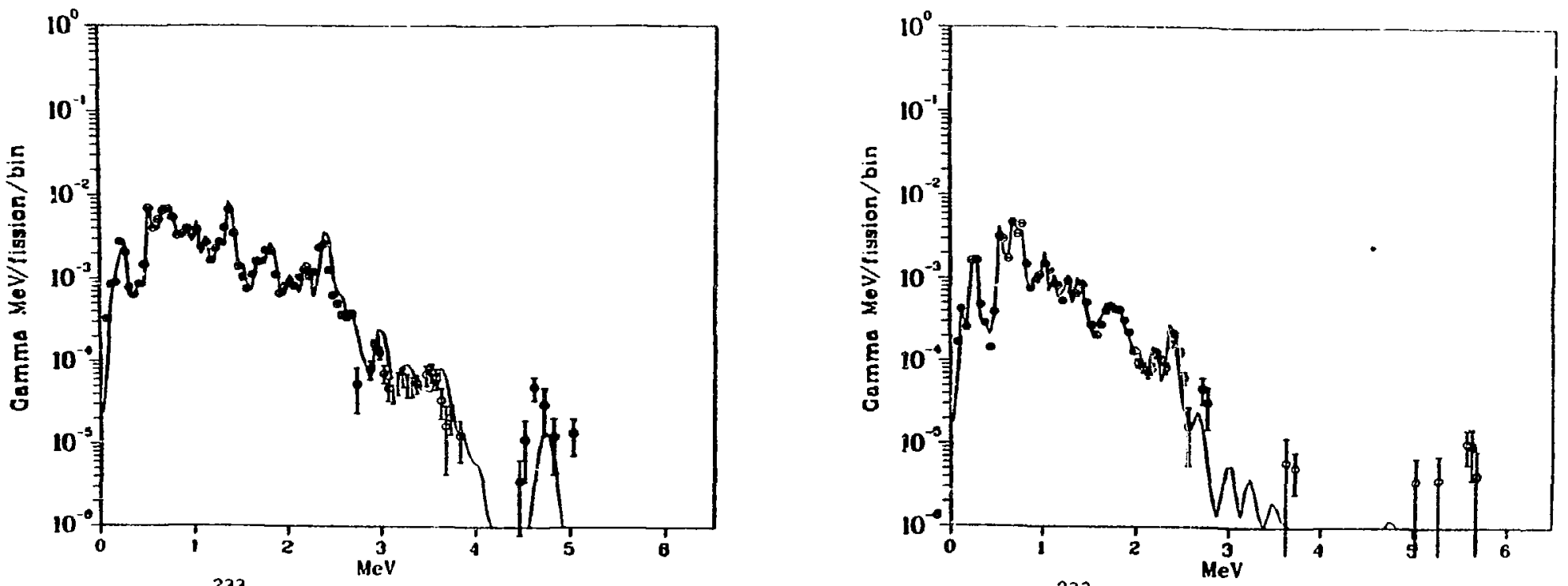

Fig. 12. ${ }^{233} \mathrm{U}$, after $23760 \mathrm{~s}$ cooling.

Fig. 13. ${ }^{233} \mathrm{U}$, after $59320 \mathrm{~s}$ cooling.

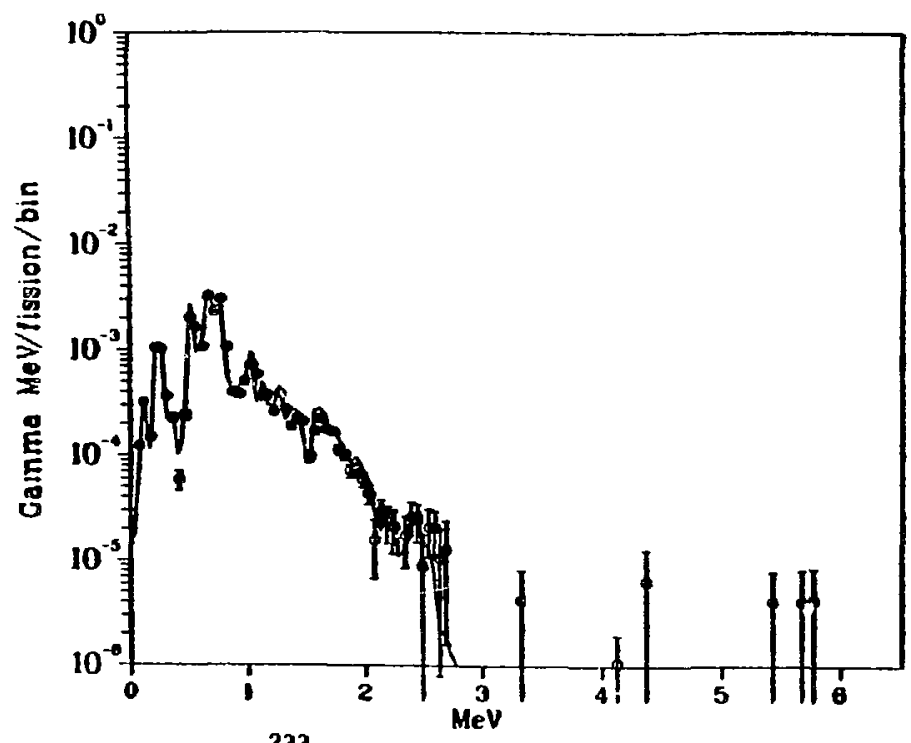

Fig. 14. ${ }^{233} \mathrm{U}$, after $96840 \mathrm{~s}$ cooling.

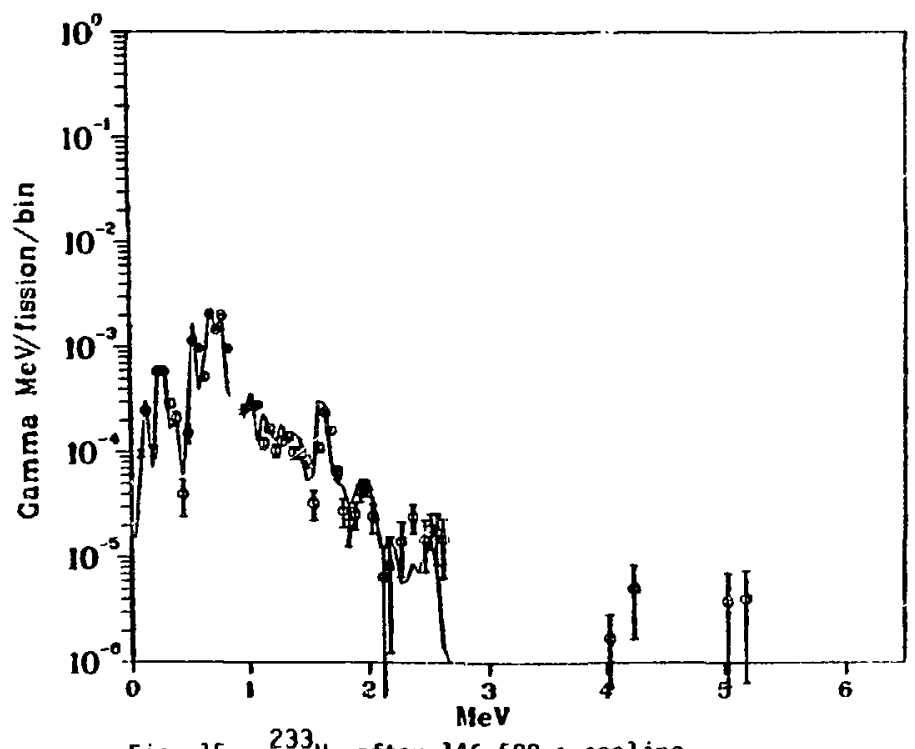

Fig. 15. ${ }^{233} \mathrm{U}$, after $146500 \mathrm{~s}$ cooling. 


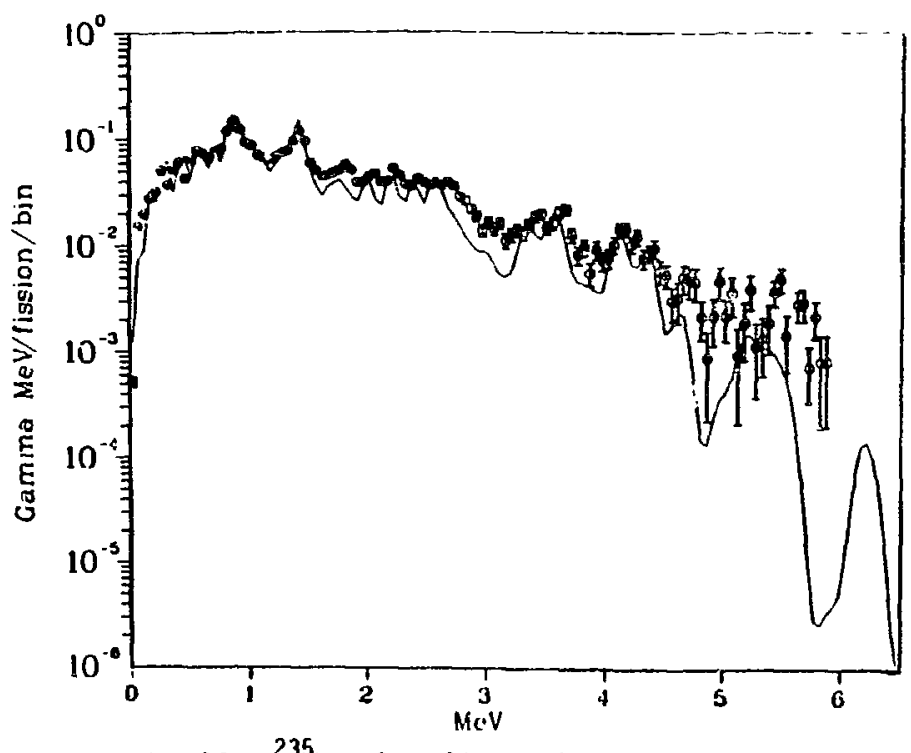

Fig. 16. ${ }^{235}$ U, after $29 \mathrm{~s}$ cooling.

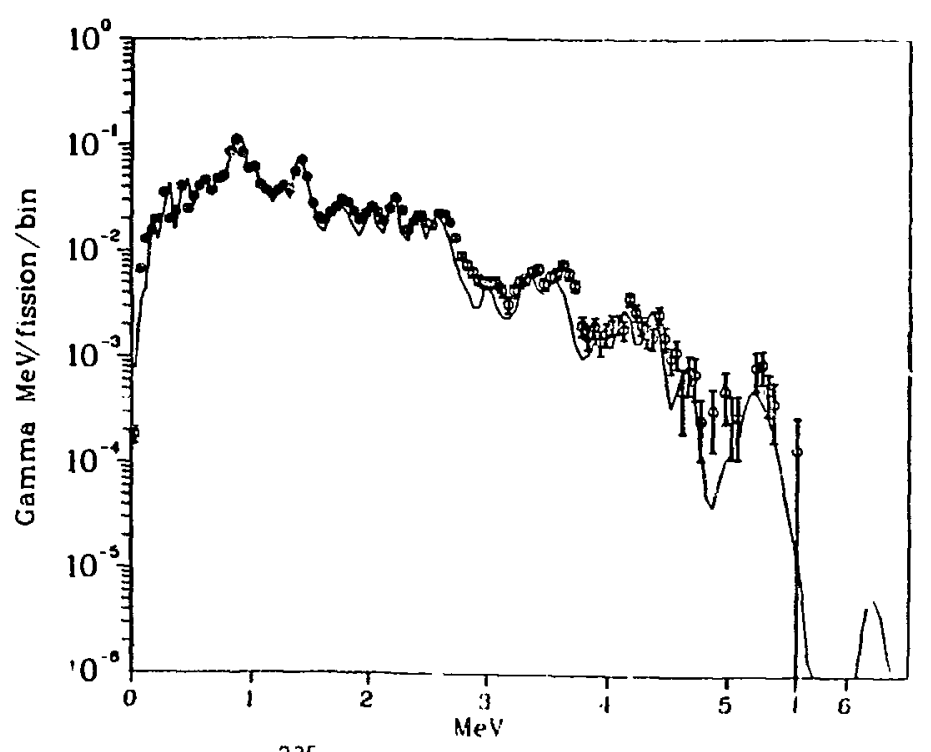

Fig. 18. ${ }^{235} \mathrm{U}$, after $284 \mathrm{~s}$ cooling.

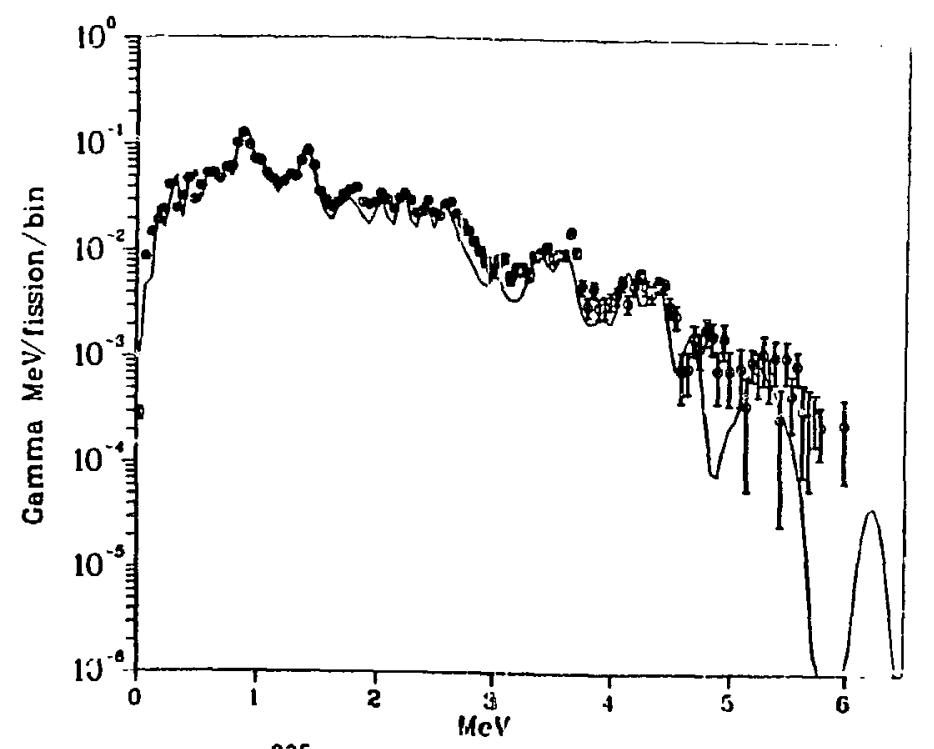

Fig. 17. ${ }^{235} U$, after 128 s conling.

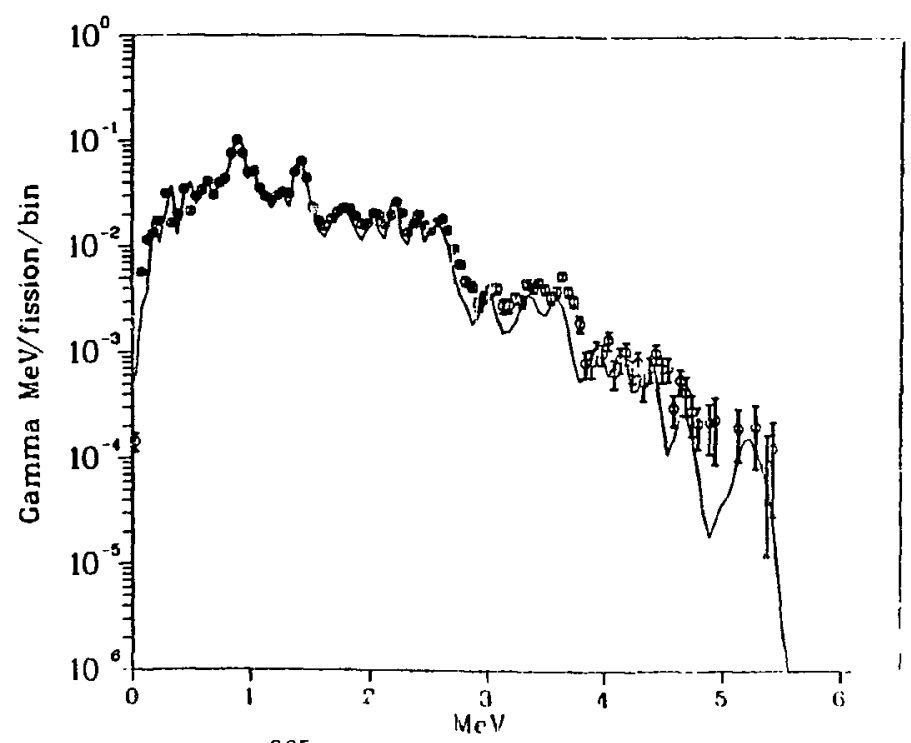

fig. 19. ${ }^{235} U$, after $538 \mathrm{~s} \cos ^{2}$ ing. 


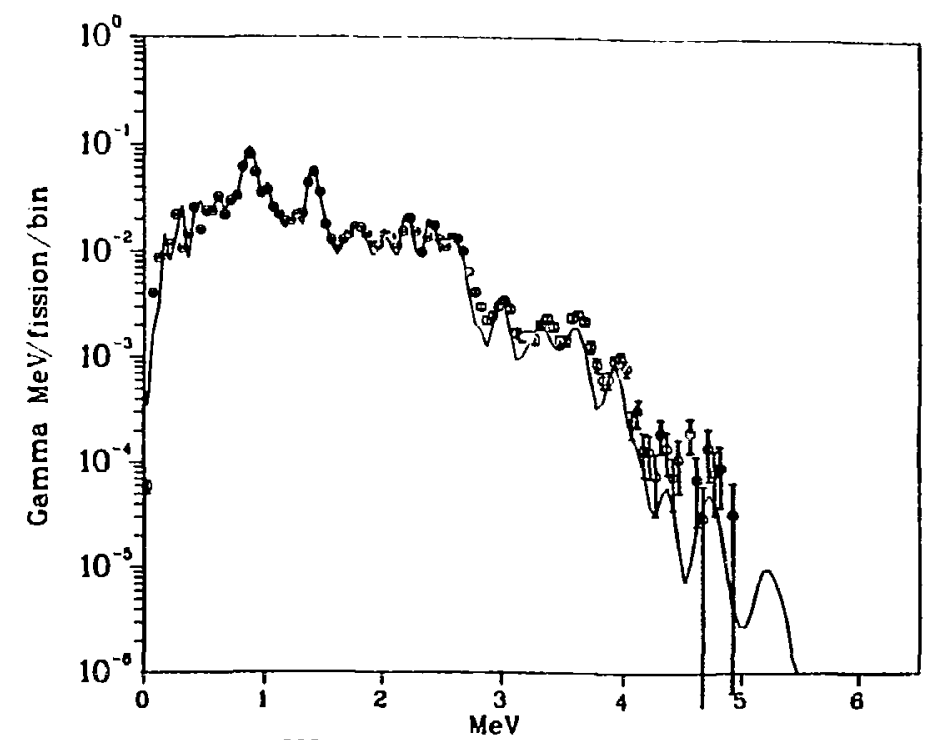

fig. $20 .{ }^{235} U$, after 1218 s cooling.

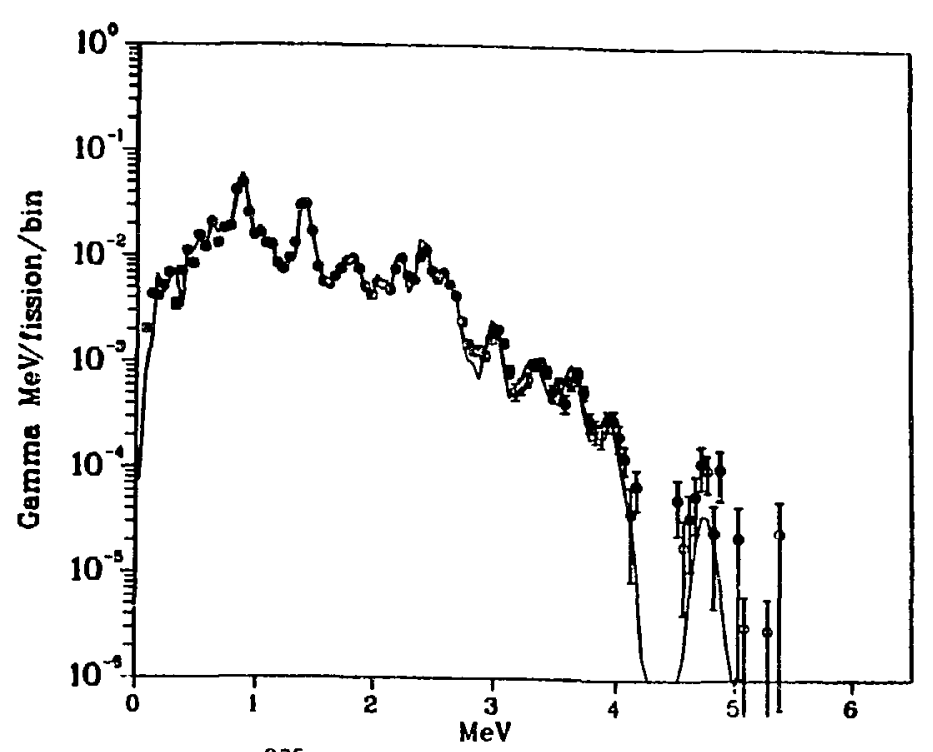

fig. 22. ${ }^{235} \mathrm{U}$, after $3930 \mathrm{~s}$ cooling.

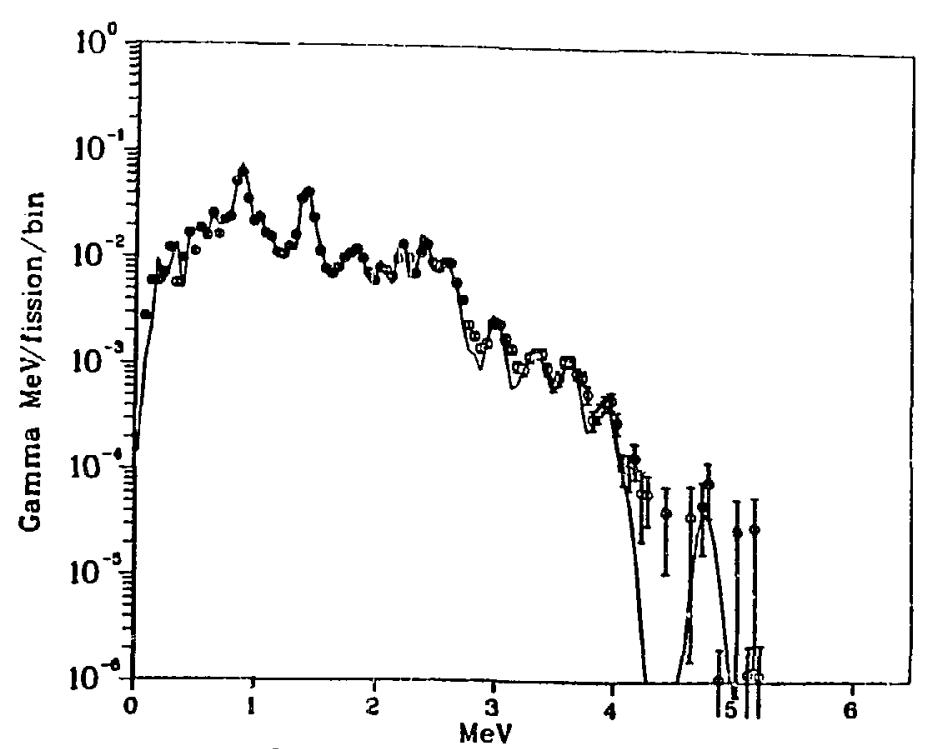

Fig. 21. ${ }^{235} \mathrm{U}$, after $2530 \mathrm{~s}$ cooling.

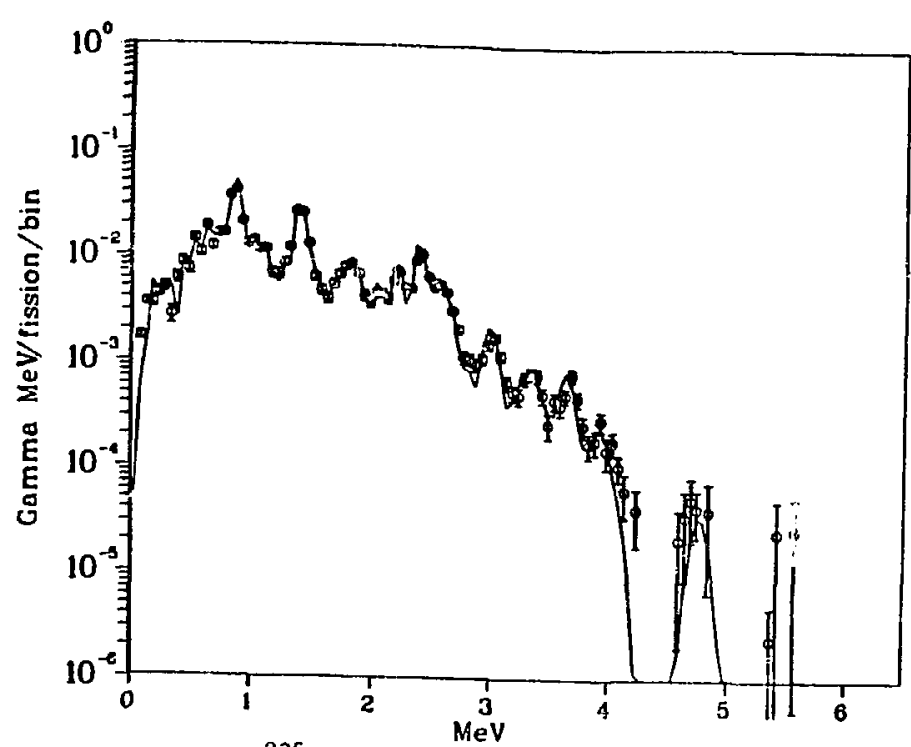

Fig. 23. ${ }^{235} \mathrm{U}$, after $5010 \mathrm{~s}$ cooling. 


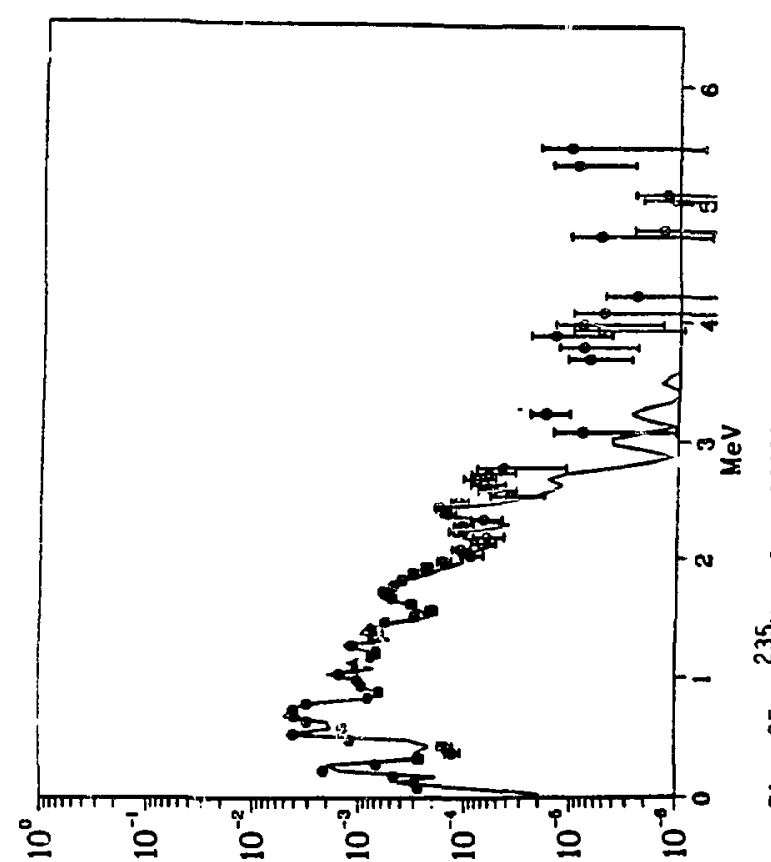

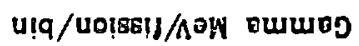

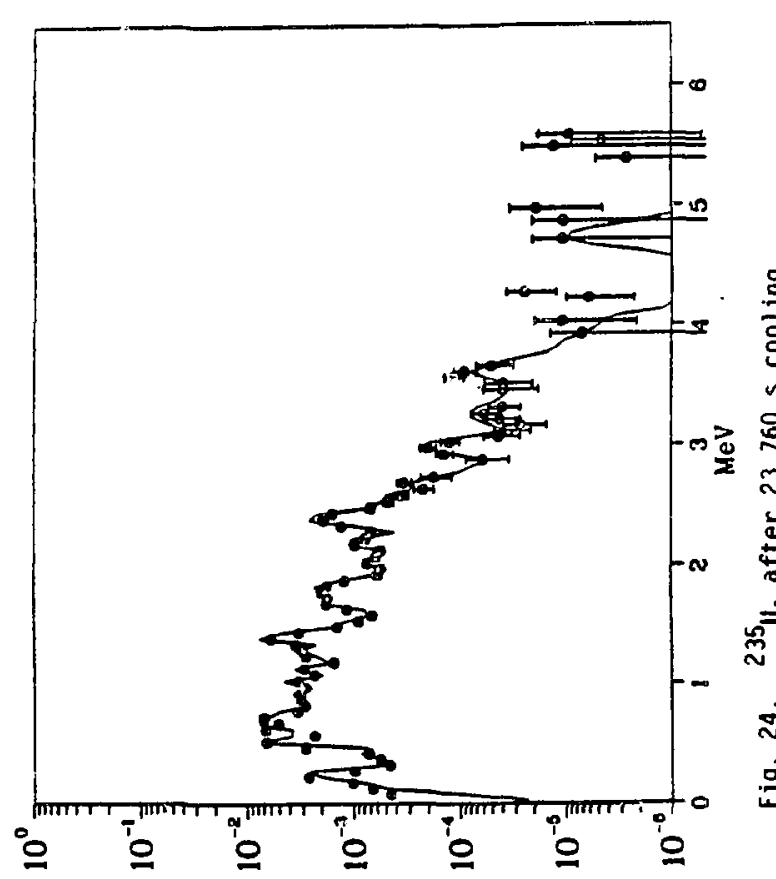

u!̣/uo!̣s! $/ \wedge$ aw ouweg
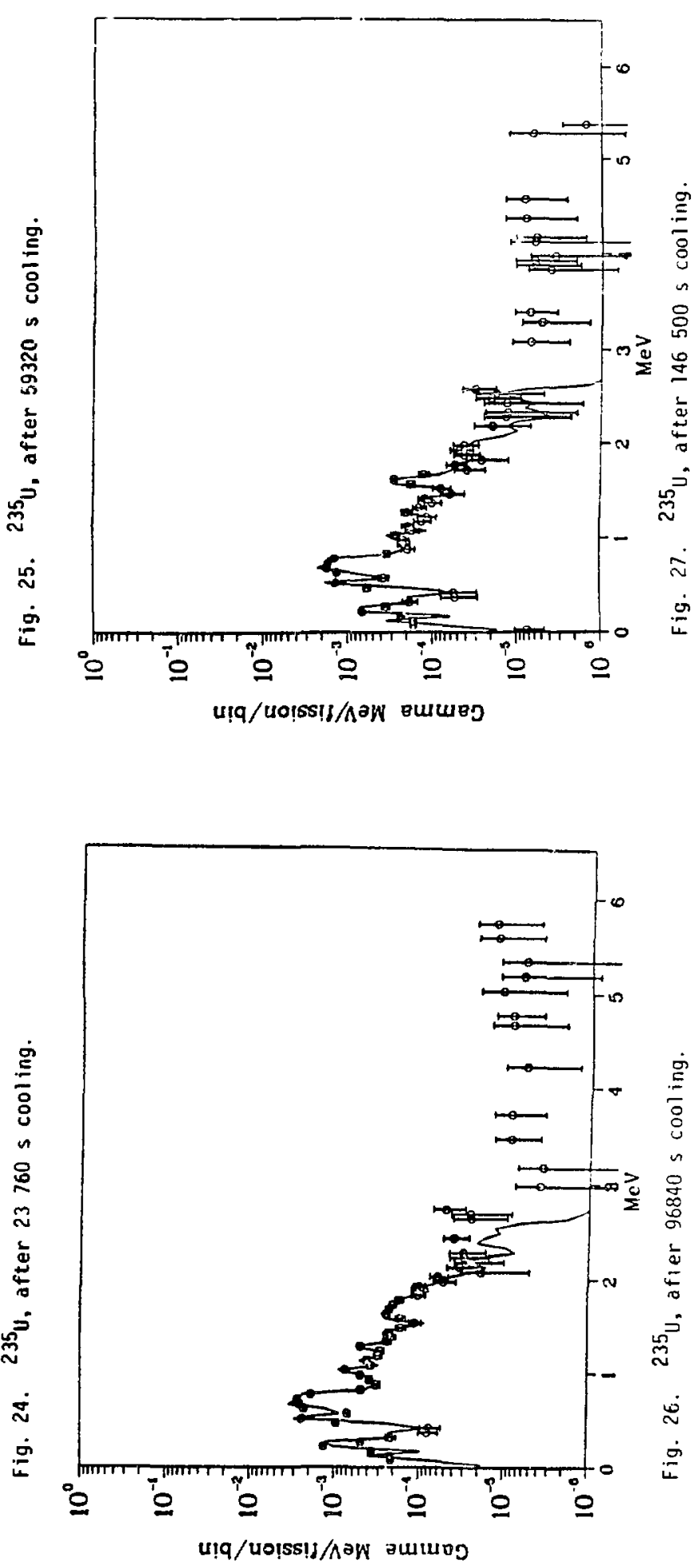


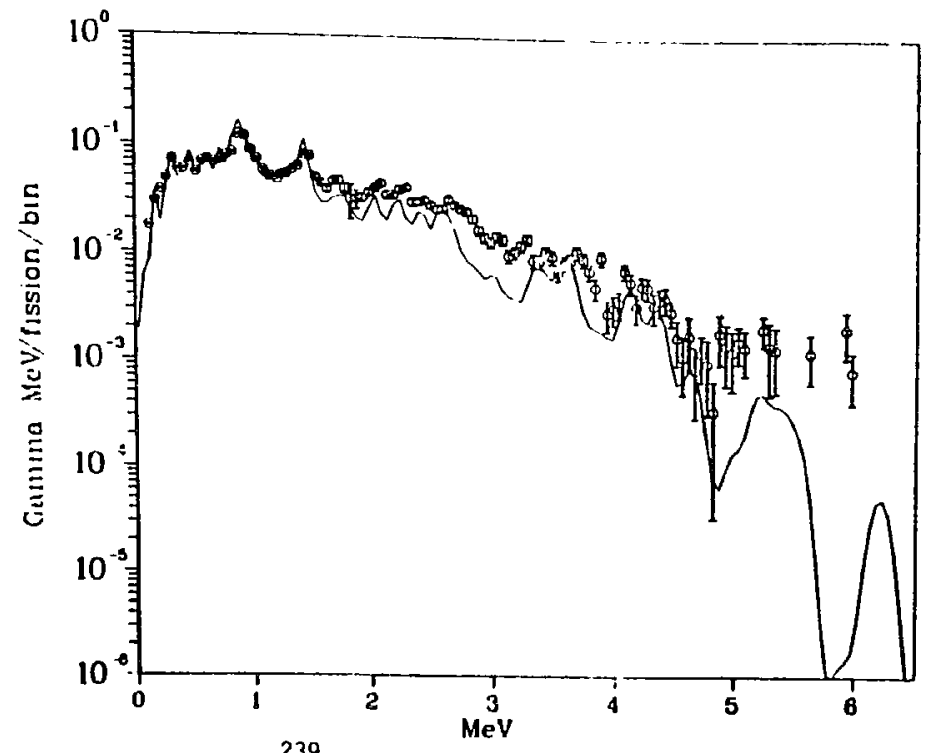

Fig. 28. ${ }^{239} \mathrm{Pu}$, after $29 \mathrm{~s}$ couling.

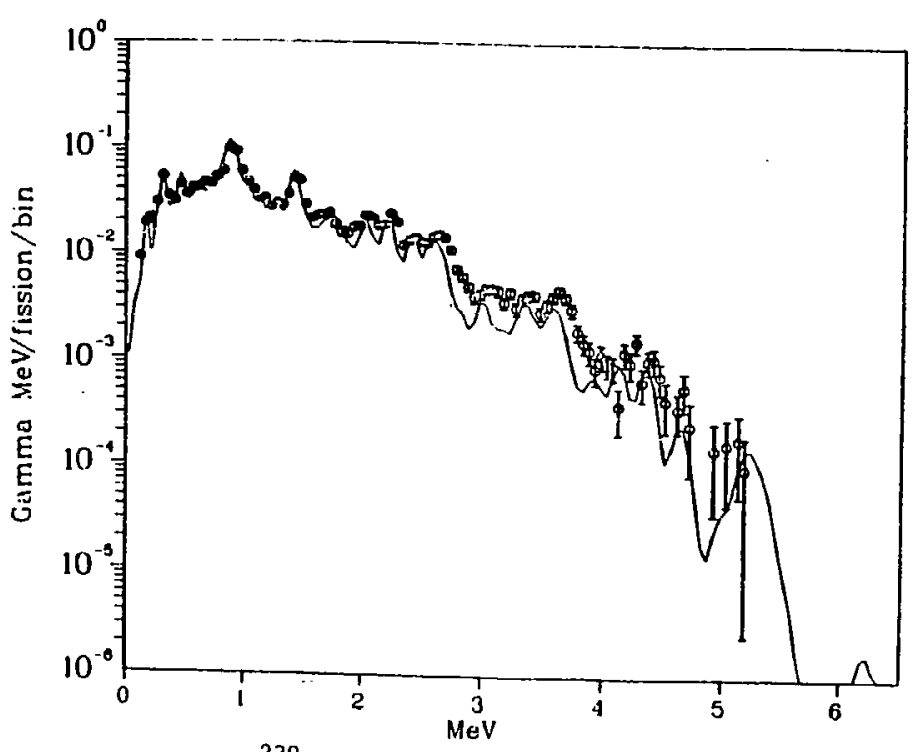

Fig. $30,{ }^{239} \mathrm{Pu}$, after $234 \mathrm{~s}$ cooling.

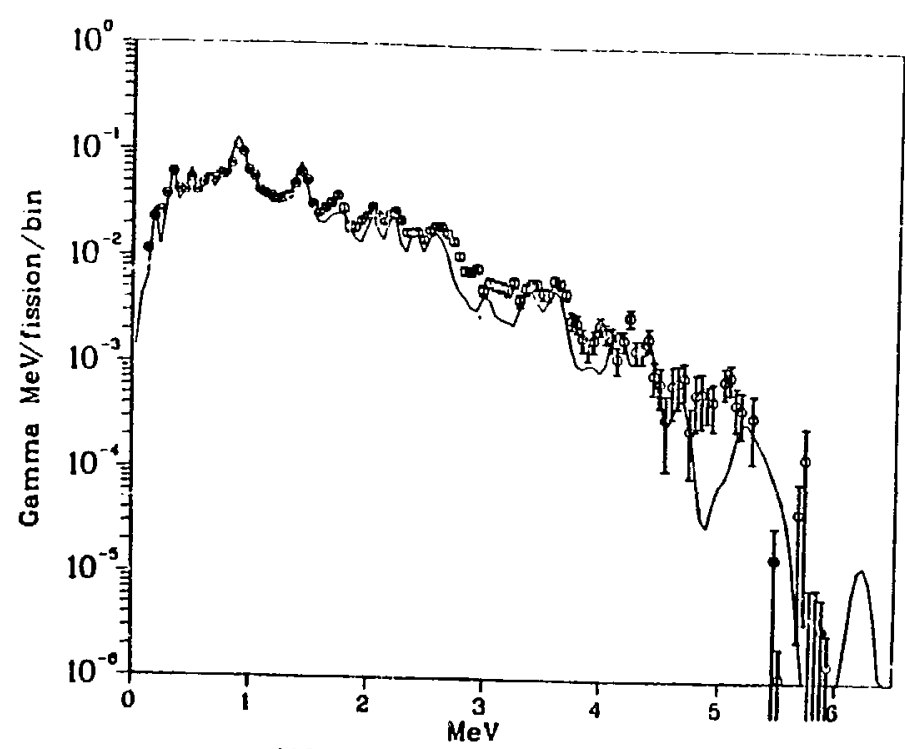

Fig. 29. ${ }^{239} \mathrm{Pu}$, after 128 s cooling.

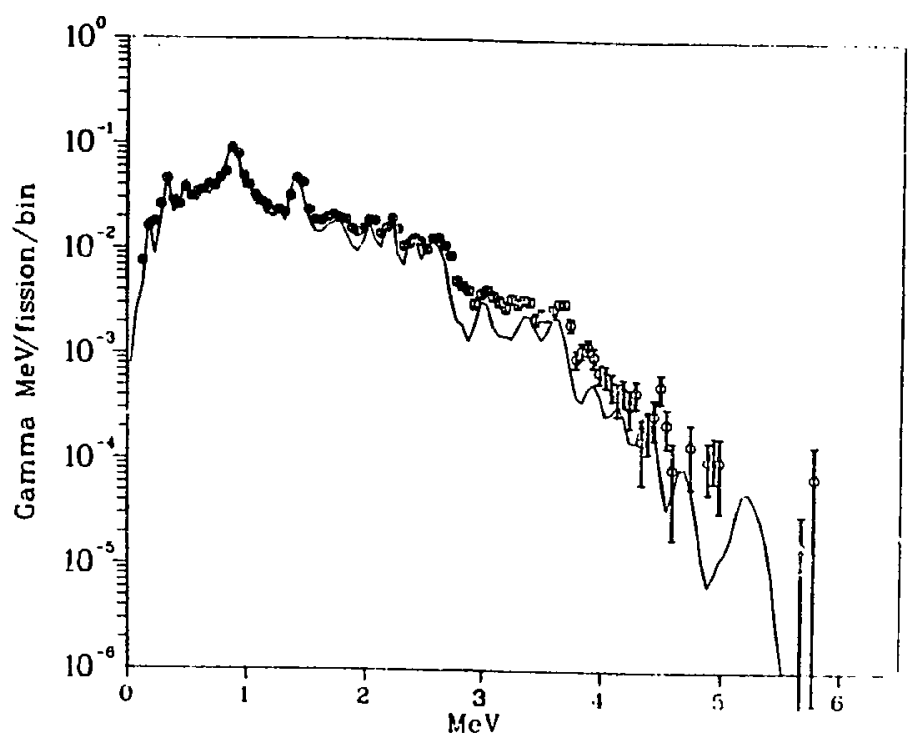

Fig. 31. ${ }^{239} \mathrm{Pu}$, after 538 s cooling. 

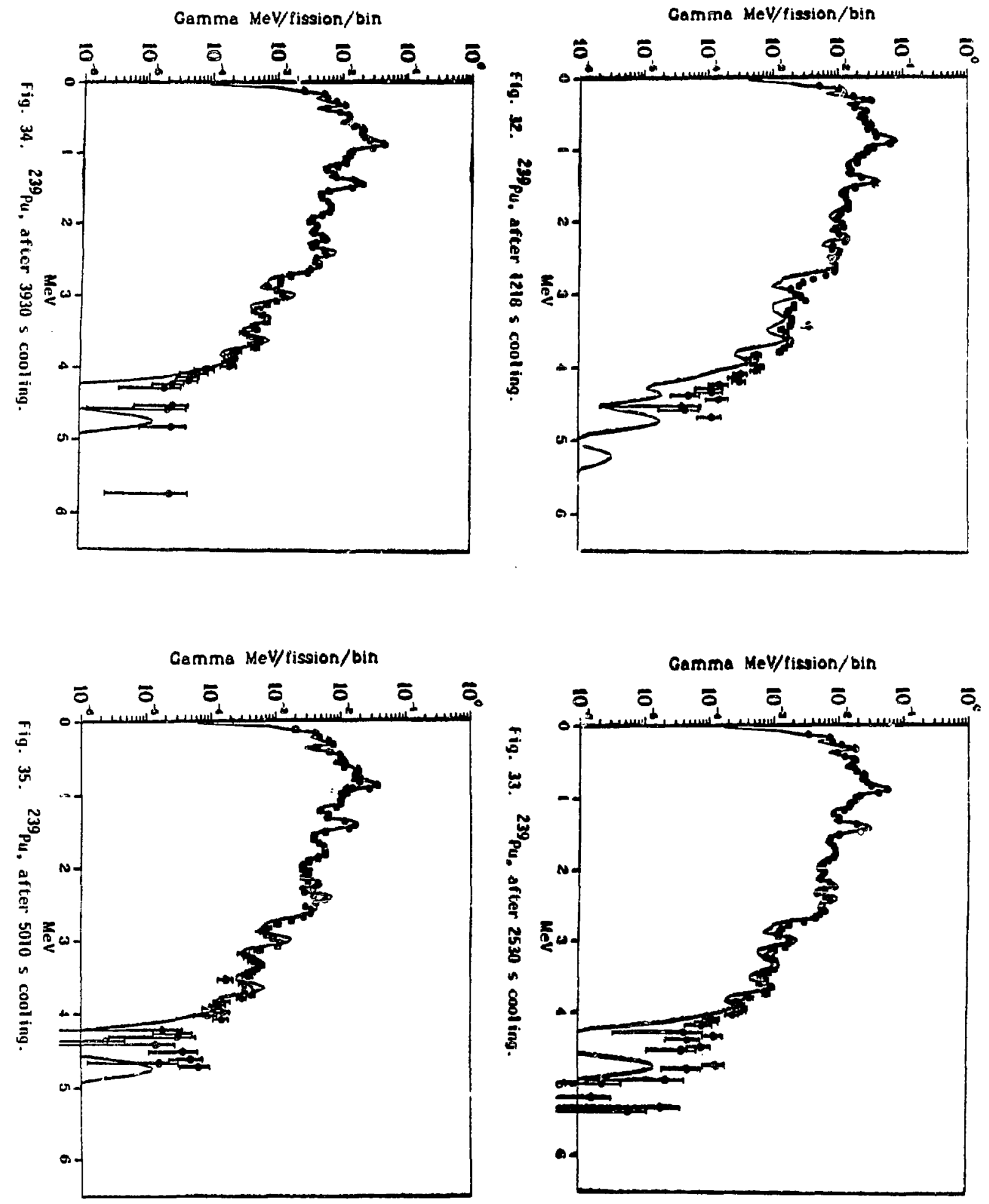


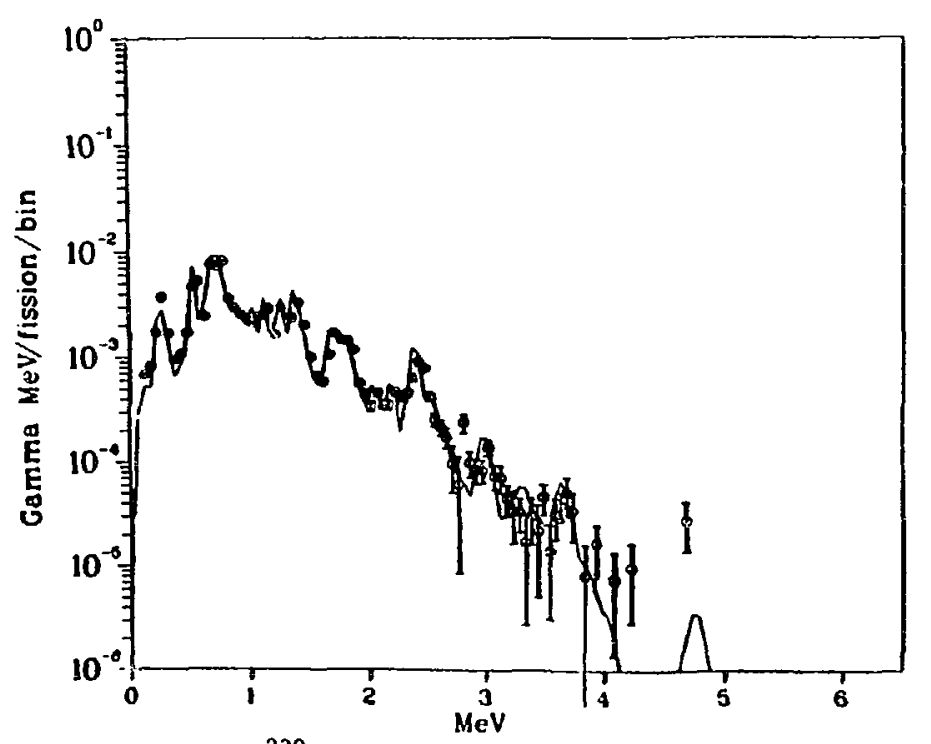

Fig. 36. ${ }^{239} \mathrm{Pu}$, after $23760 \mathrm{~s}$ cooling.

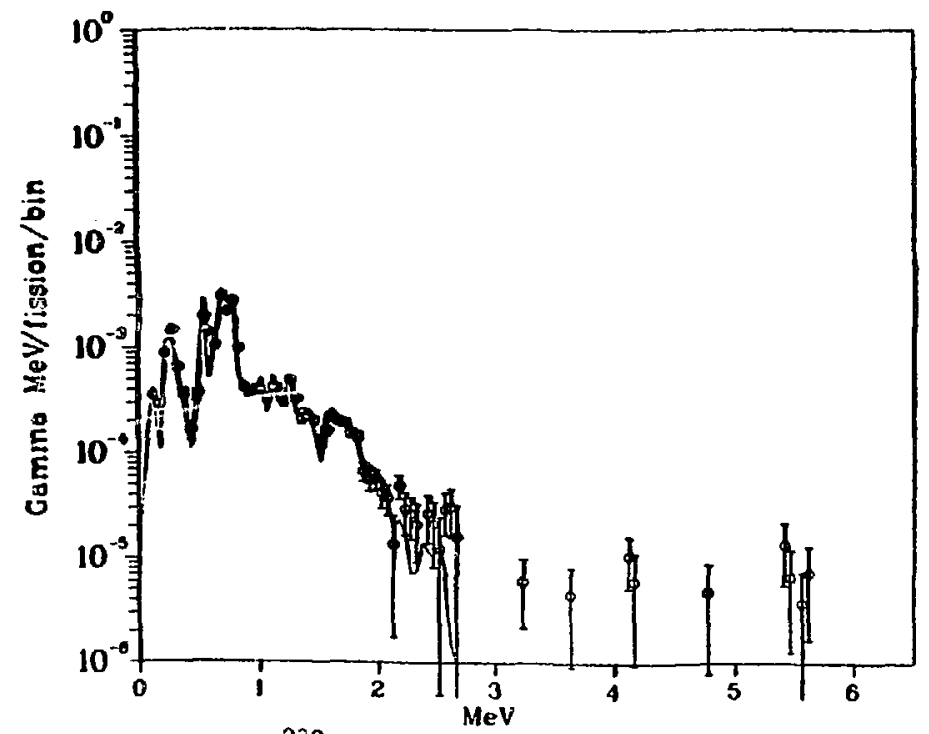

Fig. $38 .{ }^{239} \mathrm{Pu}$, after $96840 \mathrm{~s}$ cooling.

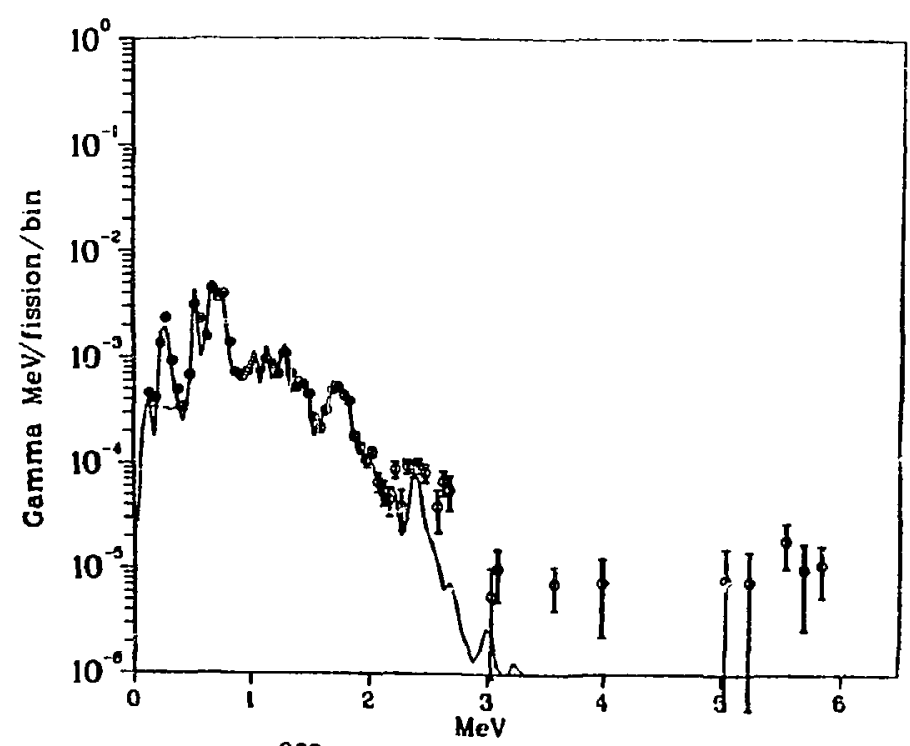

Fig. 37. ${ }^{239} \mathrm{Pu}$, after $59320 \mathrm{~s}$ cooling.

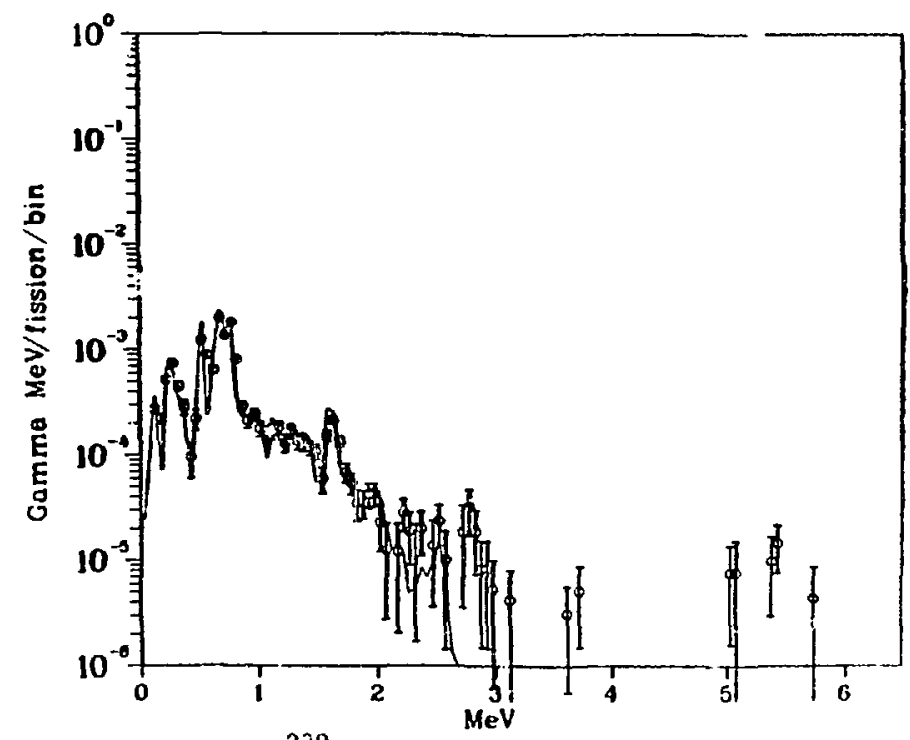

fig. $39 .{ }^{239} \mathrm{Pu}$, after $146500 \mathrm{~s}$ cooling. 